\title{
Retinoid Signaling is a Context-Dependent Regulator of Embryonic Stem Cells
}

\author{
Zoltan Simandi and Laszlo Nagy \\ University of Debrecen \\ Hungary
}

\section{Introduction}

Although the beneficial effect of certain foods, such as liver, egg or carrot is known from ancient remedies, one of the common active substances, called Vitamin A, was not identified until 1913, when it has been independently discovered by Elmer McCollum at the University of Wisconsin-Madison, and Lafayette Mendel and Thomas Burr Osborne at Yale University. Since then numerous studies have come to light documenting the effect of vitamin A on the health of the individual from birth to adult age. Hale has demonstrated among the first that deprivation of vitamin A during pregnancy induces congenital ocular malformation (Hale, 1933). Wilson and Warkany later described several other congenital malformations that occurred in fetuses from vitamin A-deficient (VAD) rats affecting the genito-urinary tract, heart and great vessels, ocular and respiratory system (Wilson and Warkany 1947; Wilson and Warkany 1950; Warkany 1954).

In 1968 Saunders and Gasseling have shown that grafting a posterior margin zone (called zone of polarizing activity, ZPA) of a chick embryo limb bud to the anterior side is able to induce an extra set of limb structures (Saunders 1968). It suggested that the ZPA region contains a diffusible morphogen. Surprisingly, retinoic acid (RA), a derivative of vitamin A, has been found to have the same effect on the anterior side of the bud (Tickle, Alberts et al. 1982). There was a doubt that retinoic acid is responsible in vivo for the phenomenon, but in 1987 Thaller and Eichele demonstrated the graded distribution of endogenous retinoic acid from posterior to anterior in the limb bud (Thaller and Eichele 1987). This was the time when retinoic acid became known as the first morphogen. Part of the truth that later RA was found to act indirectly, via induction of sonic hedgehog (Shh), and actually Shh is the true morphogen signal peptide produced by the ZPA (Riddle, Johnson et al. 1993).

Our understanding on how vitamin A and its derivatives (called retinoids) are able to have such morpho-regulatory effect on the body has dramatically increased in parallel with the evolution of molecular biology methodologies. Development of cloning strategy, establishment of cDNA library made possible the identification of a receptor for the active derivative of vitamin A by the Evans and Chambon laboratories (Giguere, Ong et al. 1987; Petkovich, Brand et al. 1987). This opened the way to clarify the role of retinoids in embryonic development. Several aspects of the retinoid signaling have been described in the last two deacades using genetically modified mice. Excellent reviews are available summarizing these in vivo results (Duester 2008; Dolle 2009; Mark, Ghyselinck et al. 2009). 
At the same time, in vivo system did not make it possible to understand the molecular mechanism in details. Thus, different cell lines were used, including embryonic carcinoma (EC) and embryonic stem (ES) cells. ES cells have the ability to resemble normal embryonic development much closer than any other cell lines and allow one to study the molecular mechanisms in the context of differentiation.

In this chapter we will focus on recent studies using embryonic stem cells as a model system to deconvolute the retinoid signaling in depth. The first section 'Retinoid signaling pathway' will introduce briefly the present accepted molecular mechanism of retinoid action. We will then go through the retinoid field in the context of ES cell pluripotency and in context of early differentiation. Unconventionally, we will discuss a set of genes that were identified in high-throughput methods as potentially retinoic acid regulated genes in ES cells, including many that were previously not implicated in RA regulation. The chapter intends to serve as a starting point to the better orientation in retinoid field and embryonic stem cells.

\section{Retinoid signaling pathway}

There are two sources of dietary vitamin A. Retinoids are immediately available to the body from intracellular stores. In contrast, precursors (such as carotenoids, mainly found in plants) first must be converted to active forms. The predominant retinoid present in the mammalian fasting circulation is the retinol. Retinol is bound to a $21 \mathrm{kDa}$ retinol-binding protein (RBP4) since it is not soluble in aqueous environments (Noy 1992). Two active derivatives, all-trans retinoic acid (atRA) and 13-cis-retinoic acid can be also found in the fasting plasma (Horst, Reinhardt et al. 1995), however at much lower concentration (for instance, atRA is 7.3-9 nmol/1 in rats) (Cullum and Zile 1985). Retinol is transported into the cytoplasm of the target cell through RBP receptor Stra6 (Kawaguchi, Yu et al. 2007). Cellular retinol binding proteins (CRBPI and II) are able to bind this cytosolic retinol in many cell types, functioning as storage of retinol. For biological effects retinol must be converted into its active forms, and that process involves two steps. Alcohol dehydrogenases (ADHs) and retinol dehydrogenases (RDHs) are catalyzing the first step, the oxidation of retinol to retinaldehyde (retinal). The second step is the oxidation of retinaldehyde to retinoic acid (RA) that is catalyzed by retinaldehyde dehydrogenases (Aldh1a1, Aldh1a2 and Aldh1a3). Retinoic acid is not produced by all cell of the body. Cells without active RA synthesis may have access to it, since it can be also taken up from the environment. RA can chemically exist as several different isomers including atRA, 9-cis-RA, 11-cis-RA, 13-cis-RA, etc, showing some tissue specific distribution. In the cytoplasm RA binds to intracellular retinoic acid binding protein 2 (Crabp2) and delivers to the nucleus where it serves as a ligand for the retinoic acid receptor - retinoid X receptor heterodimer (RAR:RXR) (reviews in (Blomhoff and Blomhoff 2006; Duester 2008; D'Ambrosio, Clugston et al. 2011).

RA acts via the activation of RAR:RXR heterodimer. RAR (RARa, RAR $\beta$ and RAR $\gamma$ ) and RXR (RXRa, RXR $\beta$ and RXRY) are two families of nuclear receptors that bind DNA and directly regulate transcription (review in (Chambon 2005)). RARs and RXRs exhibit the conserved structure of nuclear receptors, including DNA-binding domain (DBD) and Cterminal ligand binding domain (LBD) (review in (Bain, Heneghan et al. 2007)). RARs bind atRA, and the RXR partner bind 9-cis-RA. However, 9-cis-RA is normally undetectable except when retinol is present in excess (Mic, Molotkov et al. 2003). When RA binds to the RAR partner of RAR:RXR heterodimers it binds to a regulatory DNA element, called RA 
response element (RARE) (Umesono, Giguere et al. 1988; Glass 1994). The excess of RA is further oxidized and degraded by Cyp26 enzymes (Cyp26a1, b1 and c1) (Figure 1).

During embryonic development RA acts as a morpho-regulator, forming an anteriorposterior (A-P) concentration gradient (Casci 2008) and cross-talks with other key embryonic signals, especially fibroblast growth factors (FGFs) and sonic hedgehog (Shh) (Niederreither and Dolle 2008). Production by Aldh1a1-a3 and elimination together determine the local concentration of RA. Cells can read their position in the RA gradient (considering the gradient of other morphogenes) and differentiate accordingly to these signals. Knockout of both Aldh1a2 and Cyp26a1, the two key enzymes responsible to determine the local RA concentration, lead to early morphogenetic defects and embryonic lethality, indicating the importance of the precise regulation of RA concentration along the body (Niederreither, Subbarayan et al. 1999). Interestingly, Cyp26a1 expression itself is inducible by RA (Ray, Bain et al. 1997), and has two identified RARE (Loudig, Maclean et al. 2005), suggesting a negative feedback mechanism to control the RA concentration. After all, Cyp26a1 is not expressed posteriorly, where RA is the highest, raising the possibility that Cyp26a1 is controlled by another signals as well. Fibroblast growth factor (FGF) is one of the candidates that can be responsible for RA independent regulation. Accordingly, the elimination of FGF signaling was found to shift the expression of Cyp26a1 posteriorly (Casci 2008).

Present model proposes that unliganded RAR heterodimerizes with RXR and binds to DNA. In the absence of ligand the heterodimer is often complexed with corepressor proteins (such as SMRT, NCoR, etc.) (Nagy, Kao et al. 1997) and inhibits gene expression. Indeed, RA receptors are present not only where RA signaling is active, but also in anterior regions in which RA is fully absent. This is, as we will show later, true for undifferentiated embryonic stem cells, as well. Unliganded RAR:RXR thought to have a repressor function. Such active repression of RAR signaling has important regulatory role, for instance it is required for the proper head formation (Koide, Downes et al. 2001). Ligand binding stimulates a cascade of events resulting the release of corepressor complexes, recruitment of transcriptional coactivators (NCoA, $\mathrm{CBP} / \mathrm{p} 300$, etc.) and thus initiation of transcription (Figure 1) (Glass and Rosenfeld 2000; Rochette-Egly 2005). Alternatively, ligand dependent repression of target genes is also known (Horlein, Naar et al. 1995).

Strikingly, while in embryonic carcinoma (EC) or HL60 cells RA induces cell cycle arrests and differentiation (Flynn, Miller et al. 1983; Mummery, van Rooijen et al. 1987) in hepatocytes RA promotes cell proliferation (Ledda-Columbano, Pibiri et al. 2004). Cell-type specific expression of coregulators may resolve this contradiction and provide an additional context-dependent level of RA-signaling control. Little is known about the expression of RA coregulators in ES cells and early differentiation. Gudas recently showed an example for the complexity of mechanism that control RA-mediated transcription in fibroblasts versus stem cells. It was found that while $R A R \beta_{2}$ is induced in both cell types by RA; Hoxa1 and Cyp26a1 are induced only in F9 stem cells, but not in fibroblasts. Coactivators and RNA Pol II recruitment are following this pattern. Strikingly, recruitment of Suz12 (a polycomb protein), H3K27me3 (repressive epigenetic modification), H3K9 and K14 acetylation (activation) and methylated CpG islands are just partly able to explain this phenomenon (Kashyap and Gudas 2010). Thus, simple gene expressional studies are not enough to clarify the context-dependent role of coregulators in cell fate commitment. Combination of single cell analysis and genome-wide screen will be required to unexplore this level of regulation. Potential applications and an outlook will be discussed briefly at the end of this chapter, in the "Future directions". 


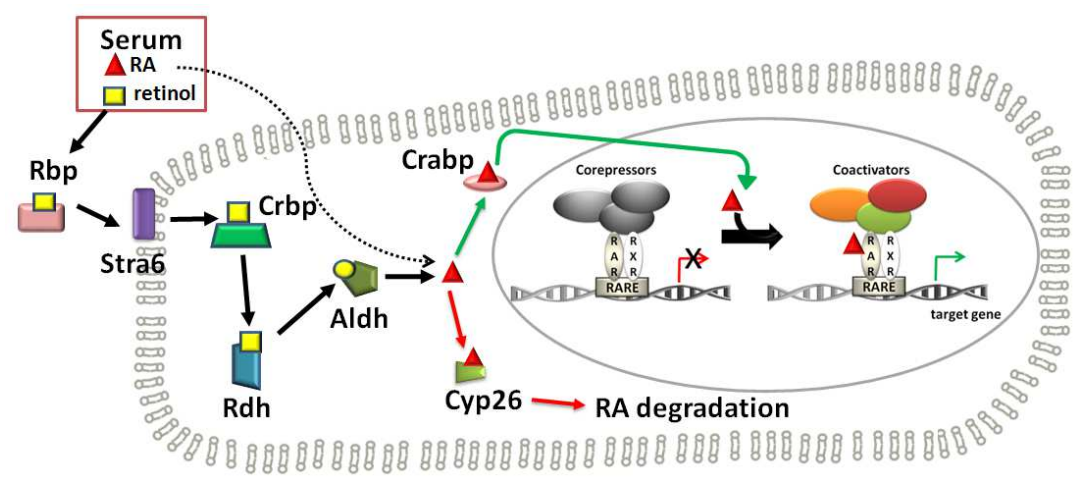

Fig. 1. Overview of retinoid signaling. Retinol is taken up from the serum by the cells via retinol binding protein $(\mathrm{Rbp})$ receptor Stra6. Intracellular retinol is reversibly oxidized to retinal by retinol dehydrogenases (Rdh) and further oxidized to biologically active RA by retinal dehydrogenases (Aldh). Alternatively, cells can take up RA from the environment. Depending on the cell necessities the unwanted RA is eliminated by Cyp26 enzymes or transported into the nucleus and activate the transcription via RAR:RXR. According to the present model, unliganded RAR:RXR bind corepressor complexes while activating ligands replace them to coactivators and promote transcriptional activation.

\section{Retinol in ES pluripotency}

In standard mammalian cell cultures blood derived fetal bovine serum (FBS) or fetal calf serum (FCS) are widely used in $1-20 \%$ to supplement the basal media providing essential factors for the cells. Media for embryonic stem cell culturing contains notable, typically $15 \%$ FBS and other factors, provided by the feeder cells. Due to the requirement of these components, ES-cell self-renewal was thought to be dependent on multifactorial stimulations. However, serum-free condition and feeder-independent cultures have been developed in recent years with success. These cultures require addition of Bmp4 and LIF (Williams, Hilton et al. 1988; Qi, Li et al. 2004). LIF can act via activation of Jak-Stat3 signaling pathway, however a complex interplay of different signaling pathways and transcription factors, such as Nanog, Oct3/4, Fgf4, Sox2, etc. are all together responsible for the pluripotency. Recently, it was shown that inhibition of FGF receptor tyrosine kinases and the inhibition of ERK cascade in combination with LIF addition are able to maintain cellular growth capacity and self-renewal of ES cells, providing a ground state to ES cells (Ying, Wray et al. 2008). These studies excluded the requirement of other extrinsic signals, such as FBS content. However, developing embryo is in direct contact with the serum, thus further studies of FBS will help us to better understand its role in embryogenesis.

Certification of defined sera usually does not include the information of its retinol content. According to our data, an ES-qualified serum contains notable retinol (Simandi, Balint et al. 2010). It is questionable whether this high retinol content of serum is playing any role in maintenance of normal phenotype of undifferentiated ES cells. Jaspal S. Khillan and his research group have focused on whether retinol affects any key signaling pathways in ES pluripotency. Interestingly, they found that it can suppress the differentiation of ESCs by up-regulating the expression of Nanog (Chen, Yang et al. 2007). The activation of Nanog by 
retinol appears to be independent of previously described LIF/Stat3, Oct3/4-Sox2, bone morphogenic proteins (BMPs), and Wnt/beta-catenin pathways. Importantly, forced constitutive expression of Nanog was shown to sufficiently prevent ES cell differentiation and render self-renewal constitutive even in the presence of active FGF/Erk signaling (references in (Silva and Smith 2008)).

The ability of retinol to influence gene expression and cell fate commitment is thought to make possible by enzymes controlling the conversion steps of the biologically active forms. In other words, only that cell is able to respond to the retinol which is expressing the necessary enzymes and receptors, listed above in section 'Retinoid signaling pathway'. Using global gene expression analyses we found, that only RDHs, Crabp1, RARs (Rary, $\operatorname{Rar} \beta)$ and RXRs (Rxra, Rxr $\beta$ ) are expressed unambiguously detectable levels in ES cells. RBPs, ALDHs and Cyp26s are present at very low mRNA levels in undifferentiated embryonic stem cells (Simandi, Balint et al. 2010). These results suggest that endogenous production of RA from the retinol content of serum is unlikely to take place in undifferentiated ES cells. Indeed, it has been demonstrated by HPLC analysis that retinol is not metabolized to RA in ES cells in the presence of LIF (Lane, Chen et al. 1999). Thus, presence of retinol in the serum is not in contrast with the importance of RA in differentiation, since endogenous RA synthesis is not taking place to induce retinoid signaling and differentiation. The fact, that RBP neutralizing antibody fail to prevent retinolmediated up-regulation of Nanog, suggests a new and independent retinol mediated pathway. Indeed, retinol can activate PI3kinase directly via insulin-like growth factor-1 (IGF-1) receptor/IRS-1 (Chen and Khillan 2010). The exact mechanism by which retinol interacts with IGF-1 receptor is not clear at this stage. As the authors hypothesize, retinol may be required to preserve the integrity of stem cells in early-stage embryos before the lineage restricted differentiation is determined. Verifying this striking mechanism, IGF1/IGFBP-1 has been already shown to facilitate the establishment of a stem-cell line (Lin, Yen et al. 2003). Further studies confirming the positive effect of retinol on stem cell culture may raise the adaptation of purified retinol in routine stem cell culturing and it may further revise the composition of serum-free media.

However active ligand of RAR is not produced in undifferentiated ES cells, important to note, that as the circulating serum, the FBS may also contain active derivatives of retinol, such as atRA or 13-cis RA in low but detectable concentration. AtRA, although fully ionized in free solution at $\mathrm{pH}$ 7.4, is uncharged when within a lipid environment (Noy 1992). Uncharged atRA is able to traverse the membrane and enter the cell (Figure 1) (Chen and Gudas 1996). It was discussed above that even ES cells express RARs and RXRs and Crabp, minimally required to respond for a stimuli. In our study we could detect atRA content of the cell culture serum and we could detect atRA by LC-MS in the cells, suggesting that atRA is taken up by the cells. Furthermore, we found that it has impact on basal gene expression level which could be inhibited by BMS493, an inverse RAR agonist (Simandi, Balint et al. 2010). In conclusion these data suggest that the artificial combination of retinol and RAR antagonist may enhance the quality of ES cultures.

\section{Retinoid receptors in undifferentiated ES cells}

Even in undifferentiated ES cells Rary, $\operatorname{Rar} \beta$, Rxra and $\operatorname{Rxr} \beta$ are expressed, however their function is not clear at this moment. According to the "unliganded receptor-repression" model their DNA binding influences the expression of adjacent genes. The binding site of 
the RAR:RXR heterodimer on the DNA is the so called RA response element (RARE). RARE is consisting two consensus half-sites separated by a variable length of DNA. The sequence of this consensus half-site is most typically 5'-AGGTCA-3' (Balmer and Blomhoff 2005). According to the relative direction of the half-sites, direct repeat, inverted repeat and everted repeat can be distinguished (Honkakoski and Negishi 2000). Type II nuclear receptors, such as RARs and RXRs typically bind to a direct repeat (DR), separated by 1, 2 or 5 nucleotides (called DR1, DR2, DR5, respectively). The RAREs tipically located in target genes, however large number of DR2-type elements are present within Alu repeats (Vansant and Reynolds 1995) (Figure 2 show some of the well known RA target genes and their RAREs).

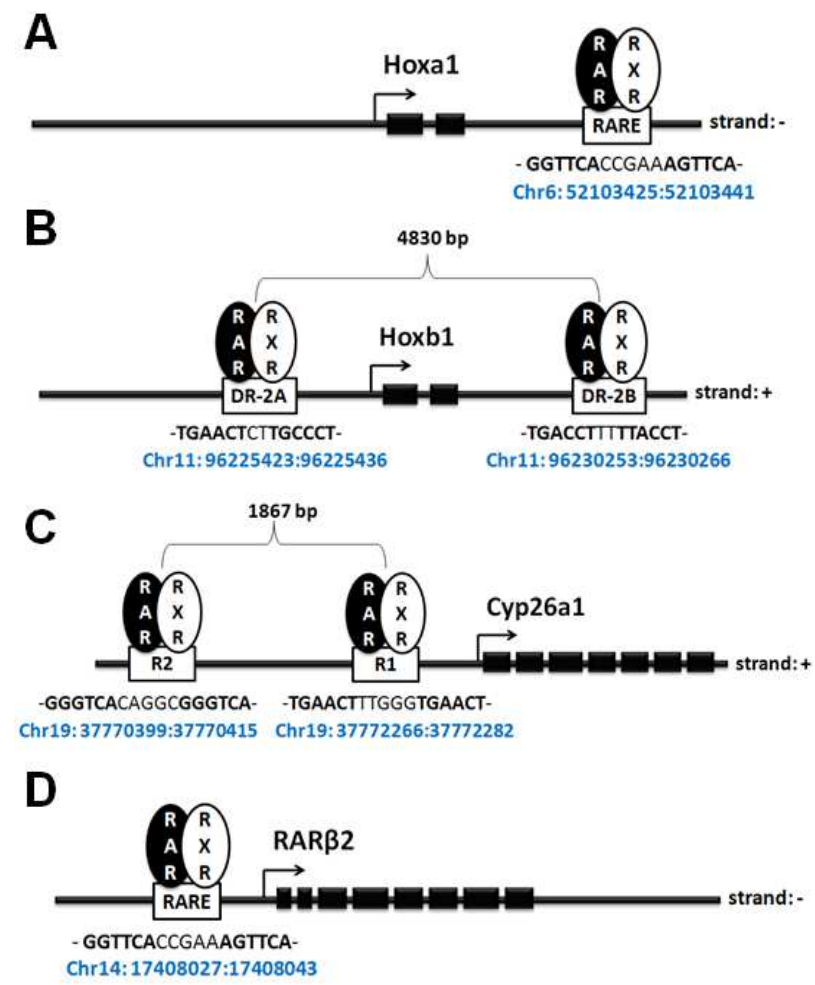

Fig. 2. RARE elements of well-known RA target genes. RAR binding occurs most typically on DR5 (Hoxa1, Cyp26a1, RARß2) and DR2 (Hoxb1) elements.

Chromatin immunoprecipitation (ChIP) is a powerful and widely applied technique for detecting the association of individual proteins with specific genomic regions. ChIP can be combined with microarray technology to identify the location of specific proteins on a genome-wide basis (called ChIP-chip) (Aparicio, Geisberg et al. 2004). A recent study has performed ChIP-chip on mouse embryonic fibroblasts and ES cells overexpressing tagged Rary (Delacroix, Moutier et al. 2010). Rary is the dominantly expressed subtype of RAR in ES cells, thus it confirms the biological relevance of this analysis. 354 target loci bound by the RAR were identified in MEFs and 462 loci in undifferentiated ES cells. These sites 
obviously do not cover the full repertoire, but as this was the first large-scale study, it served many striking results. First, it was found that only a minority of the 354 MEF loci were present in ES cells, suggesting cell-specific occupancy of RAR binding. This can be an important mechanism contributing to the distinct of retinoid signaling seen in different cell types. Not unexpectedly, in ES cells RAR was found to occupy genes with a wide variety of functions: pluripotency (Oct3/4, Lin28, or Utf1), differentiation (Lefty1, Lefty2), important signaling pathways (Nodal, Notch4, sonic hedgehog pathway components, several FGF), a more systematic discussion of regulated genes will be provided in the next section. In MEF cells RAR occupancy (ChIP-chip data) and RA regulation (microarray) has been analyzed together, showing that only small subset of RAR bound genes were regulated by RA. In undifferentiated ES cells such dataset is still not available. It cannot be completely excluded that formaldehyde cross-linking or overexpression of Rary gives its artificial detection by ChIP. However, many of those RAR bound, but not regulated genes were found to be regulated by RA in other cell types, suggesting the good source of data and a highly cell type and context dependent regulation. Moreover, part of the genes, bound by unliganded RAR, showed H3K4me3 (associated with active chromatin) and expression. Data is lacking to show whether there is a partial repression in case of these genes or unliganded RAR binding do not influence their expression at all. Latter would suggest that unliganded RAR silences only small subsets of bounded target genes. This is at least partly in contrast with the previously mentioned "unliganded RAR - corepressors recruitment" model (shown on Figure 1) and confute one at this moment to unambiguously predict which gene and which cell type will respond to the stimuli. In the same study the sequence of RAR-bound loci has been compared. Interestingly, majority of the loci did not contain consensus DR1, -2 or -5 elements, rather compromised one or several anomalously spaced consensus half sites. Strikingly, there was no correlation between the presence/absence of recognizable DR elements and RA regulation. Bioinformatic analyses are considering the sequence diversity of RAR binding sites and the varying distance between the direct repeats only in a limited level. Genome-wide RAR binding studies in different cell types combined with advanced bioinformatic analysis of target loci may help to build a better prediction model and further investigate the biological aspects of different binding sites and the potential role of epigenetic state of these regions. One of such pioneer study (Mahony, Mazzoni et al. 2011) will be discussed in the next section.

\section{Retinoic acid induced downregulation of stem cell pluripotency and differentiation induction}

The moment that we revoke LIF from the media of undifferentiated ES cells results in the spontaneous differentiation of cells. This can be further induced by allowing them to form aggregates, called embryoid bodies (EB). We have looked for the early changes during the four day embryoid body formation using genome-wide expressional analysis and found $\sim 1000$ genes to be regulated. Important genes involved in retinoid signaling, such as Stra6, Aldh1a2, $\operatorname{Rar} \beta$, etc. are not among them, only the expression of the RA induced-RA eliminator Cyp26a1 is elevated, suggesting that RA signaling is not activated yet in this stage and the incidental RA level is actively cleared away. This is in correlation with the findings that presence of RA decreases the viability of blastocyst (Huang, Shen et al. 2003) and explain the importance of uterine Cyp26a1 activity in the maintenance of pregnancy, especially during the process of blastocyst implantation (Han, Xia et al. 2010). Potentially, an 
RA-independent, FGF signaling controlled Cyp26a1 expression may be responsible for this for RA clearance in day 4 EBs. This explains why Cyp26a1 could upregulate in the presence of RAR inverse agonist BMS493. In contrast, following the post-implantation RA is sorely needed. Absence of RA in this stage cause serious malformations, including axial rotation, shortens along the anterioposterior axis, disturbed limb bud development, finally resulting early embryo death (Niederreither, Subbarayan et al. 1999).

Currently, the effector molecules and cascade signaling of the early retinoid signaling in the vertebrate embryo are barely known. Mechanistic studies showed that RA is not just initiating the differentiation, but also actively decrease the pluripotency via binding to RARE in Oct3/4 promoter (Pikarsky, Sharir et al. 1994) and regulation of LIF-signaling (Tighe and Gudas 2004). Indeed, Oct3/4 is not changing significantly between day 0 and day 4 in our data, but it is actively down-regulated following RA-treatment. In the same time, neural marker DCX becomes upregulated (Simandi, Balint et al. 2010). This suggests clearly the importance of retinoic acid-free (but not retinol-free) environment to the undifferentiated embryonic stem cells. The importance of RA in pluripotency can be studied from a different viewpoint, namely, whether retinoid signaling is able to influence the cell reprogramming. Yamanaka and contributors have shown that introduction of four factors (Oct3/4, C-Myc, Klf4 and Sox-2) into mouse embryonic fibroblast (MEF) cells induce the reprogramming of the differentiated cells and driving back them to embryonic stem cell-like cells, called induced pluripotent stem cells (iPSC) (Takahashi and Yamanaka 2006). A recent study has investigated how different nuclear receptors influence the iPS generation from MEFs. This screen included 19 nuclear receptors, among them Rara, Rary and Rxra. Surprisingly, none of the overexpressed retinoid receptors influenced significantly the obtained iPS colony numbers (Heng, Feng et al. 2010). Importantly, this study did not use ligands or antagonists to activate (or repress) the overexpressed receptors.

More is known about the ES differentiation promoting effect of RA. Over the years, many RA-regulated differentiation pathways have been discovered first in embryonic carcinoma (EC) and then adopted to ES cells as well. The most studied mouse EC cell lines include F9 cells, which can be induced by RA to differentiate into primitive, parietal, and visceral endodermal cells; and P19 cells, which can differentiate to endodermal and neuronal cells upon RA treatment. ES cells can be induced to differentiate into a number of different cell types; many of which require RA treatment (Soprano, Teets et al. 2007).

To understand in depth how retinoic acid is able to drive a given differentiation pathway, one should identify a set of regulated genes by high-throughput methods. Here, a very important issue is the applicable concentration of retinoic acid. Typically, a regulated gene shows dose dependent effect. From this dose dependent curve one can determine the half maximal effective concentration $\left(\mathrm{EC}_{50}\right)$ of the given gene. This value may vary in case of other target genes. Thus, it can happen that with the application of lower retinoic acid concentration one will induce only the most responsiveness genes (lower $\mathrm{EC}_{50}$ ). A solution for this problem can be a high RA concentration that will give the maximal response (saturation). However, this posing is just partly correct. First, in the embryonic development RA grade has very important effect in the anterior-posterior patterning and deep impact on cell fate commitment. This can be true for stem cell differentiation as well. Strikingly, there is no systematic study available using different concentration of RA comparing sets of regulated genes genome-wide. Theoretically, a low concentration of RA results in the

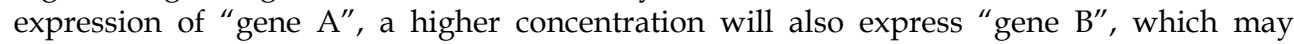
negatively affect the expression of "gene $A$ " by a negative feedback mechanism. 
Limited number of studies demonstrated the dose-dependent effect of RA on a given pathway. For instance, it was shown that higher concentrations of RA induce a dorsal phenotype, while lower concentrations of RA induced a more ventral phenotype during RA induced neural differentiation (Okada, Shimazaki et al. 2004). Not only the concentration, but also the timing of RA signal might be very important. According to the established protocols, different cell types (such as adipocyte, pancreatic cell, neural cells, primordial germ cells, etc.) requires RA signal in various time-points during their differentiation (Bost, Caron et al. 2002; Bibel, Richter et al. 2007; Eguizabal, Shovlin et al. 2009).

The exact molecular events that lead from a pluripotent stem cell to a fully differentiated cell following RA treatment are yet to be determined. Considering the above discussed timeand dose-dependent effect, gene expressional studies can determine the early signaling pathways induced by retinoic acid. We have performed such a study on 4 day-old embryoid bodies treated with $5 \mu \mathrm{M}$ ATRA for 12 hours and identified 70 annotated genes that were regulated at least 2-fold. At first glance it seems a low number of genes, but another independent study could detect similarly only 96 significantly differently expressed genes (Mahony, Mazzoni et al. 2011). Gene expressional studies cannot clearly classify sets of genes that are directly regulated by RAR. A new method, namely ChIP-Seq, combines chromatin immunoprecipitation (ChIP) with parallel DNA sequencing to identify global binding sites for any protein of interest (Johnson, Mortazavi et al. 2007). A recently published paper investigated the ligand-dependent dynamics of RAR binding during early differentiation using ChIP-Seq. In the absence of RA, ChIP-Seq enrichment could be detected at 1822 sites in embryoid bodies. After 8 hours of exposure to RA this number did not really changed (enrichment at 1924 sites). The most frequent motifs were DR2 and DR5. Confirming the previously discussed ChIP-chip dataset, only 507 sites bound constitutively RAR. This is further query the accepted model of constitutively binding RARs. More strikingly, in the same study they could detect a ligand-dependent shift in RAR's preference from DR0 and DR1 (absence of ligand) to DR5 (presence of ligand).

\section{Retinoic acid driven signaling pathways in embryonic stem cells}

Vitamin A-deficient and genetic animal models revealed the importance of retinoic acid signaling in embryonic development and organogenesis. In early development, RA participates in the organization of the trunk by providing an instructive signal for posterior neuroectoderm, foregut endoderm and a permissive signal for trunk mesoderm differentiation. At later stages, RA contributes to the development of the eye and other organs (reviewed in (Duester 2008). Presumably, in vitro experiments in stem cell cultures are able to reveal the in vivo molecular targets of retinoid action during the development. Indeed, we will show hereinafter that genes identified in cell culture experiments match in vivo findings. However, one should assume that these in vitro cultures are not able to perfectly mimic the spatio-temporal events.

Binding of RA to its receptor induces differentiation mainly via one of the following mechanisms: 1) Initiate changes in interaction of RAR:RXR and co-regulators (SMRT, NCoR, $\mathrm{NCoA}, \mathrm{CBP} / \mathrm{p} 300$, etc.), resulting transcription of primary target genes; 2) Induces expression of transcription factors (Hox, $\mathrm{Cdx}$, etc) and other signaling molecules, resulting transcription of secondary target genes. Regulation of non-coding RNAs may serve as additional level of retinoid action (Rossi, D'Urso et al. 2010); 3) Alters interactions with proteins involved in epigenetic regulation (Kashyap, Gudas et al. 2011). Furthermore, there 
are proteins that bind at or near RAREs resulting a more complex mechanism of retinoid action (for review, see (Gudas and Wagner 2011).

In the followings we will discuss the potential role of genes identified in ChIP-chip study of ES cells (Delacroix, Moutier et al. 2010), in day 2 EBs by ChIP-Seq study (Mahony, Mazzoni et al. 2011) or in our microarray study (Simandi, Balint et al. 2010), focusing especially on those which were found in more than one of these studies. In fact, the overlap between the results is remarkable. The results of these experiments provide a list about genes that are primary (ChIP-chip, ChIP-Seq) or secondary response to RA (microarray) considering the technical limitation of such experiments. Based on the published biological functions, we divided arbitrarily some of the genes into functional subgroups. An asterisk $\left({ }^{*}\right)$ mark genes where previously identified or predicted RARE could be identified. Following the gene name, an arrow marks the atRA effect for the expression of the given gene $(\uparrow, \downarrow)$, up and down, respectively.

\subsection{Regulators of RA metabolism}

The following genes are well known players in the retinoid metabolism (see Figure 1 and 3). At the same time many of them are involved in the proper eye function, and very likely important in its development. For more details about retinoid signaling in embryonic eye development look for recent reviews in (Duester 2009), (Cvekl and Wang 2009).

Cyp26a1* (cytochrome P450, family 26, subfamily a, polypeptide 1) ( $\uparrow$ )

Cyp26 enzymes have been shown to restrict the availability of RA to the transcriptional machinery (review in (Pennimpede, Cameron et al. 2010). HPLC and LC-MS-MS identified 4-OH-RA, 4-oxo-RA and 18-OH-RA and other oxidized products formed as metabolites by Cyp26a1 (Chithalen, Luu et al. 2002). Cyp26a1 expression is directly regulated by RA, and presumably independently regulated by FGF (Casci 2008). Microarray analyses revealed that RA-treated Cyp26a1 -/- ES cells exhibited lower mRNA levels than wild-type ES cells for genes involved in differentiation, particularly in neural and smooth muscle differentiation (Langton and Gudas 2008). One intriguing possible role of Cyp26a1 is to regulate the formation of waves or pulses of RA during the dynamic development of some structures, most notably the hindbrain (Sirbu, Gresh et al. 2005).

Dhrs3 (dehydrogenase/reductase (SDR family) member 3), also known as retinal shortchain dehydrogenase/reductase (retSDR1) $(\uparrow)$

It has been first described in cone photoreceptors suggesting its possible responsibility for reduction of all-trans-retinal in photoreceptor outer segments that serve as the first step in the regeneration of bleached visual pigments (Haeseleer, Huang et al. 1998). Furthermore, it was found to be expressed also in placenta, lung, liver, kidney, pancreas, and retina; many of these tissues known to actively metabolize retinol. Thus, it suggests that Dhrs3 acts as a generic all-trans-retinol dehydrogenase in many tissues, ensuring that deleterious levels of all-trans-retinal do not accumulate. It was later demonstrated that Dhrs3 is induced by RA in a wide array of cell lines derived from different human tissues and a recent study has shown that Dhrs3 respond oppositely to RA antagonists. Using morpholino knockdown and mRNA over-expression, this study demonstrated that Dhrs3 is required to limit RA levels in the embryo, primarily in the central nervous system (CNS) (Feng, Hernandez et al. 2010). These together suggest that Dhrs3 is an RA-induced feedback inhibitor of RA biosynthesis, and it acts very similarly than Cyp26a1. Whether the RA function is direct or indirect in 
Dhrs3 regulation remained to be undetermined. Both ChIP-chip and ChIP-Seq analysis could identify Dhrs3; however typical binding site was not identifiable.

Rarb* (retinoic acid receptor, beta) $(\uparrow)$

The various RAR subtypes $(\alpha, \beta, \gamma)$ are widely but differentially expressed during murine embryonic development, and most tissues express one or more of the subtypes and isoforms during development in different combinations (Dolle 2009). The expression of Rar $\beta$ gene is spatially and temporally restricted in certain structures in the developing embryo (segmented brain (r7), hypothalamus, ventricular neuroepithelium, pigmented epithelium, proximal bronchi, myocardium, etc.), suggesting that $\operatorname{Rar} \beta$ could play specific roles during morphogenesis. In contrast, mice lacking all isoforms of $\operatorname{Rar} \beta$ develop normally and there is no obvious alteration in the spatial pattern of expression of Hox genes (Luo, Pasceri et al. 1995). These experiments demonstrate that $\operatorname{Rar} \beta$ is not absolutely required for embryonic development, maybe due to the redundancy in their role among the RAR isoforms.

Rbp1* (retinol binding protein 1, cellular), also known as CRBP1 ( $\uparrow)$

As it was discussed previously, retinol and retinaldehyde in the cytoplasm are associated with cellular retinol-binding proteins (CRBPs). CRBP1 is the most widespread, but it displays some tissue specificity (Dolle, Ruberte et al. 1990). Functional analysis of CRBP1 suggested its role in retinol storage and release where high levels of RA are required for specific morphogenetic processes (Ghyselinck, Bavik et al. 1999). However, CRBP1-deficient mice did not show any morphological defects, did not result altering organogenesis and CRBP1 ablation did not change RA-dependent gene expression, indicating that absence of CRBP1 is not life-threatening, at least under conditions of maternal vitamin A dietary sufficiency (Ghyselinck, Bavik et al. 1999).

Stra6 (stimulated by retinoic acid gene 6) $(\uparrow)$

Existence of a cell-surface receptor for RBP has been predicted since the mid-1970s. In 2007, Kawaguchi and coworkers could identify Stra6 that acts as a high affinity cell surface receptor for RBP (Kawaguchi, Yu et al. 2007), however Stra6 is not expressed in all retinoid metabolizing tissues. Interestingly, cell culture experiments have shown that Stra6expressing cells, preloaded with retinol, are able to release more retinol into the culture medium than cells without expresson of Stra6 (Isken, Golczak et al. 2008), suggesting that Stra6 acts as a bidirectional transporter of retinol. Potentially, Stra6 depending on intracellular retinol/retinoic acid concentration, coordinate retinol uptake /removal, thus avoiding cells to take up toxic amount of retinol. Stra6 mutation was found to lead severe congenital abnormalities in humans, including congenital heart defects, mental retardation and lung hypoplasia (Pasutto, Sticht et al. 2007).

\subsection{Regulators of body axis patterning}

Retinoic acid has been described as a first morphogen (Slack 1987). Indeed, it is responsible for the regulation of several genes implicated in body axis determination. However, the embryonic axis formation is a very complex process, regulated by additional factors, such as Wnt, Shh, Bmp and FGF signaling (Meyers and Martin 1999; Diez del Corral and Storey 2004). Final outcome of the differentiation is the resultant of these signaling pathways. Most of the following genes are well known RA signaling targets, the reason for listing them here is to demonstrate the role of RA in body axis determination. 


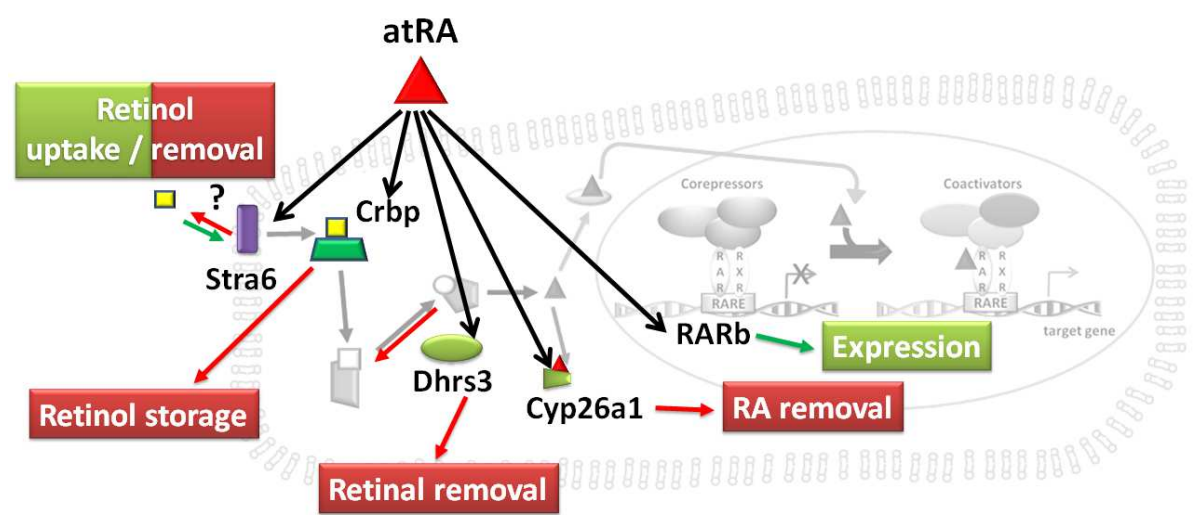

Fig. 3. Effect of all-trans retinoic acid treatment on the retinoid pathway in EBs. Addition of atRA induce its removal via multiple pathway (in red). Stra6 may responsible to eliminate the intracellular retinol, Crbp1 may hold back the retinol from further steps, Dhrs3 participates in retinal removal, while Cyp26a1 can degrade the produced RA. These mechanisms may have a role to protect the blastocyst from the toxic effect of retinoids.

Cdx1* (caudal type homeobox 1 ) ( $\uparrow$ )

The $C d x$ genes (Cdx1, 2 and 4) are relatives of Hox genes (see below) and believed to derive from a common ProtoHox ancestral cluster (Chourrout, Delsuc et al. 2006). Cdx regulate anterior-posterior (AP) vertebral patterning, at least in part, through direct regulation of Hox gene expression via $\mathrm{Cdx}$-binding sites, which are often found in clusters throughout the Hox cluster (Gaunt, Drage et al. 2008). Prior work has shown that Cdx1 is target of Wnt, RA and FGF signaling, suggesting that Cdx1 is responsible to convey the activity of these signaling molecules to Hox genes. Indeed, RARE and Lef/Tcf-response elements (LRE) has been identified in the proximal promoter of $\mathrm{Cdx} 1$. Interestingly, mutation of LRE greatly reduce the induction of $\mathrm{Cdx} 1$ by $\mathrm{RA}$, demonstrating a requirement for Wnt signaling in the regulation of this gene by retinoids (Beland, Pilon et al. 2004). Retinoic acid plays a key role in early stages of $C d x 1$ expression at embryonic day 7.5. Surprisingly, $C d x 1-/-$ mice are viable and fertile, however showing anterior homeotic transformations of vertebrae (Subramanian, Meyer et al. 1995). These abnormalities are concomitant with posterior shifts of Hox gene expression domains in the somitic mesoderm.

In ES cell derived EBs Cdx1 expression is increasing, peaking between day 2 and day 3 which is the reported window of hemangioblast and blood fate specification (day 3 to day 4 of EB differentiation). Ectopic expression of Cdx1 in differentiating EBs up-regulated Hoxa and Hoxb posterior cluster genes (Hoxa6, Hoxb8, Hoxb9) (McKinney-Freeman, Lengerke et al. 2008).

Hox (homeobox) genes $\left({ }^{*}\right.$ in the text) $(\uparrow)$

Hox genes are organized in gene clusters (Hoxa, Hoxb, Hoxc, and Hoxd) and show a strict coordinated expression, reglated by among others $\mathrm{Cdx}$ genes. Retinoic acid is not only through the regulation of $\mathrm{Cdx}$, but also directly a well-established regulator of Hox genes along the anterior-posterior axis in higher animals. Genes in the 3' ends of Hox clusters are induced by RA, while 5' Hox genes are not induced by RA (Langston and Gudas 1992; 
Langston, Thompson et al. 1997). Indeed, microarray and ChIP-Seq studies identified several members of the Hox family (Hoxa1*, a2*, a3*, a4, a5*, a10 and Hoxb1*, b2*, b3*, b4*, $\mathrm{b} 5^{*}, \mathrm{~b} 6^{*}$, Hoxc4 etc.). Hoxc and Hoxd clusters are not induced upon RA treatment in ES cells and day 2 or day 4 old EBs. Several RARE has been identified in the Hox cluster by ChIPSeq, many of them have been described in previous publications (Popperl and Featherstone 1993; Dupe, Davenne et al. 1997; Packer, Crotty et al. 1998; Huang, Chen et al. 2002).

\section{Lefty1 (left right determination factor 1) $(\uparrow)$}

A distinctive and essential feature of the vertebrate body is a pronounced left-right asymmetry (review in (Mercola and Levin 2001). Left-right asymmetric signaling molecules in mammals include three transforming growth factor beta (TGFbeta)-related factors, Nodal, Lefty 1 and Lefty 2 that are responsible for the mirror-image anatomy. They are all expressed on the left half of developing mouse embryos. Nodal acts as a left-side determinant by transducing signals through Smad and FAST and by inducing Pitx2 expression on the left side. Lefty proteins are antagonists that inhibit Nodal signaling (Hamada, Meno et al. 2001). Nodal and Lefty are expressed in the pancreas during embryogenesis and islet regeneration. In vitro studies demonstrated that Nodal inhibits, whereas Lefty enhances, the proliferation of a pancreatic cell line (Zhang, Sterling et al. 2008).

Meis1 and Meis2* (myeloid ecotropic viral integration site) $(\uparrow)$

Homeodomain proteins of the Meis subfamily are expressed dynamically in several organs during embryogenesis and exert potent regulatory activity through their interaction with Hox proteins and other transcription factors. Meis1-deficient embryos have partially duplicated retinas and smaller lenses than normal. They also fail to produce megakaryocytes, display extensive hemorrhaging, and die by embryonic day 14.5 (Hisa, Spence et al. 2004). In addition, Meis1-deficient embryos lack well-formed capillaries, although larger blood vessels are normal. Definitive myeloerythroid lineages are present in the mutant embryos, but the total numbers of colony-forming cells are dramatically reduced (Azcoitia, Aracil et al. 2005).

Pbx2* (pre B-cell leukemia transcription factor 2) ((-), see in the text)

It has been found that Pbx2 -/- embryos are born at the expected Mendelian frequencies and exhibit no detectable abnormalities in development and organogenesis (Selleri, DiMartino et al. 2004), however they show limb abnormalities (Capellini, Di Giacomo et al. 2006). Supporting its role in this phenomenon, its elevated expression in limb buds after RA treatment has been demonstrated. Retinoic acid response element in the promoter of $\mathrm{Pbx} 2$ has been identified in both ChIP-chip and ChIP-Seq study, even without ligand activation. However it seems to be not regulated by atRA in ES cells or EBs according to the microarray data, suggesting a more context dependent regulation of this gene by RA. As Pbx proteins have been shown to dimerize with Hox proteins and act as a cofactor, we included here (Moens and Selleri 2006). Pbx2 is believed to be involved in the control of proximodistal axis formation in mouse (Capellini, Zewdu et al. 2008).

Tshz1 (teashirt zinc finger family member 1$)(\uparrow)$

Tshz1 is detected from E9.5 in the somites, and also present in the spinal cord, limb buds and branchial arches. Tshz1 -/- mice exhibit Hox-like vertebral malformations and homeotic transformations in the cervical and thoracic regions, suggesting that Tshz1 and Hox genes are involved in common pathways to control skeletal morphogenesis (Core, Caubit et al. 
2007). Previous studies suggested Tshz1 as an RA regulated gene, however direct evidence was not shown yet.

\subsection{Testis development, spermatogenesis, female fertility}

Generation of putative primordial germ cells (PGCs) has been reported during the differentiation of mouse and human ESCs in in vitro systems using RA (reviewed in (Zhou, Meng et al. 2010)). In vivo PGCs come from the proximal epiblast and migrate subsequently into the mesoderm, the endoderm and the posterior of the yolk sac (Bendel-Stenzel, Anderson et al. 1998). The mechanisms responsible for the pluripotent epiblast cells to become PGCs involve bone morphogenetic protein 2 (Bmp2), Bmp4, Bmp8b, Prdm1 and Prdm14 (Ying and Zhao 2001; Edson, Nagaraja et al. 2009). Migration of PGCs requires interferon-induced transmembrane proteins 1 and 3, Kit ligand and Cxcl12 (Molyneaux, Zinszner et al. 2003). Germ cells continue to proliferate by mitosis upon arriving in the genital ridge. Spermatogonial lineage does not enter meiosis before puberty, and the proliferation is inhibited by androgens. In contrast, germ cells in the female gonad continue to proliferate by mitosis and enter meiosis. These are raising the evidence of testicular meiosis-preventing and ovarian meiosis-inducing factors. Initiation of meiosis in the fetal ovary has been suggested to require retinoic acid (Bowles, Knight et al. 2006). Germ cells fail to enter meiosis and remain undifferentiated in embryonic vitamin A-deficient ovaries, suggesting that retinol regulates the initiation of meiosis I ( $\mathrm{Li}$ and Clagett-Dame 2009). Another study revealed, that RA-degrading enzyme Cyp26b1 in fetal testis is responsible to delay meiosis until postnatal development (Koubova, Menke et al. 2006). However, RA acts too widely in mammalian development to account, by itself, for the cell-type and temporal specificity of meiotic initiation. The following RA regulated genes have been found related to germ cell development; many of them only partly characterized yet.

Agpat3* (1-acylglycerol-3-phosphate O-acyltransferase 3) also known LPAAT3 ( $\uparrow)$

Agpat3 was shown to have both lysophosphatidic acid acyltransferase (LPAAT) and lysophosphatidylinositol acyltransferase (LPIAT) activities. It is mainly expressed in the liver, kidney, and testis. Present studies suggest its role in PI (phosphatidylinositol) production of the testis. Interestingly, expression of Agpat3 in the testis is enhanced significantly in an age-dependent manner (Yuki, Shindou et al. 2009).

Nrip1 (Nuclear receptor interacting protein 1) also known as RIP140 ( $\uparrow$ )

A nuclear protein that specifically interacts with the hormone-dependent activation domain AF2 of nuclear receptors. Mice null for Nrip1 gene are viable, but females are infertile because of complete failure of mature follicles to release oocytes at ovulation stage. Heterozygous females are only partially affected (White, Leonardsson et al. 2000).

Rec8* (REC8 homolog (yeast)) ( $\uparrow$ )

Gene expression of Rec8 is strictly confined to spermatocytes and spermatids in male mouse and oocytes in female mouse. Restricted expression pattern of Rec 8 mRNA implies its essential role in meiosis in both sexes of mammals (Lee, Yokota et al. 2002). It was found that Rec8 is a key component of the meiotic cohesin complex. During meiosis, cohesin is required for the establishment and maintenance of sister-chromatid cohesion, for the formation of the synaptonemal complex, and for recombination between homologous chromosomes. Importantly, Rec8 -/- mice are born in sub-Mendelian frequencies and both sexes have germ cell failure causing sterility ( $\mathrm{Xu}$, Beasley et al. 2005). 
Stra8* (stimulated by retinoic acid 8$)(\uparrow)$

Encodes a protein that is crucial for mammalian germ cells to enter into pre-meiotic stages. Microarray analysis of whole murine embryonic ovary and postnatal testis time course data revealed a single peak of Stra8 expression in each organ at the onset of meiosis; at E14.5 in the ovary and 10 days postpartum in the testis (Hogarth, Mitchell et al. 2011). Stra8 is specifically expressed in mammalian germ cells before their transition from mitosis to meiosis and its expression is observed only in the postnatal testis. Stra8 associates with DNA and possesses transcriptional activity (Tedesco, La Sala et al. 2009). Stra8 mRNA and protein were induced in cells treated by all-trans and 9-cis retinoic acids in P19 embryonal carcinoma cells (Oulad-Abdelghani, Bouillet et al. 1996), however using Aldh1a2 -/- mice (lacking RA synthesis) it was found that Stra8 expression is detectable even in the absence of RA (Kumar, Chatzi et al. 2011).

The following genes are also regulated by atRA and could be detected with ChIP-chip or ChIPSeq. They are related to fertility, testis or germ cells, but due to the limited available data, they are not discussed here in details: $\mathbf{W d r 4 0 b}(\uparrow), \operatorname{Nr0b1}(\uparrow), \operatorname{Cxcl12}(\uparrow), \operatorname{Kit}(\uparrow), \operatorname{Tcp} 11(\uparrow)$.

\subsection{Neuroectodermal cell fate commitment}

Other chapters of the book prominently construe with the neural differentiation of stem cells. Present protocols are widely using RA to induce the neural differentiation of stem cells; however the exact mechanisms remained largely unknown yet. The fact that endogenous RA is starting to synthetize in mouse embryo after forebrain and midbrain neuroectoderm induction is raising the possibility that RA is actually not required for neural induction (Duester 2008). However, RA induced Hoxa1 activity is clearly essential for the neuronal differentiation (Martinez-Ceballos and Gudas 2008).

The following genes were found to be related to the neural differentiation or functioning. They may have role in the neural specification only. Some of them are putatively involved in the eye development as well.

Ankrd43* (ankyrin repeat domain 43) ( $\uparrow$ )

Very limited information is available for this gene. It is among those seven genes which were found to be differentially expressed in progenitors in the lateral and medial ganglionic eminences (LGE and MGE). LGE progenitors produce striatal projection neurons and olfactory bulb interneurons, whereas MGE as well as caudal ganglionic eminence (CGE) progenitors produce cortical and hippocampal interneurons. Thus, its RA regulation suggests the role of RA in neural specialization (Tucker, Segall et al. 2008).

Glra2 (glycine receptor chloride channel, alpha 2 subunit) ( $\uparrow)$

This gene mediates inhibitory neurotransmission in the spinal cord, brainstem and retina. During development, Glra2 is expressed in the retina, in the spinal cord, and throughout the brain. Mice with a targeted deletion of Glra2 show no gross morphological or molecular alterations in the nervous system. (Young-Pearse, Ivic et al. 2006).

Gpr124 (G protein-coupled receptor 124) ( $\uparrow$ )

GPR124 is highly expressed in central nervous system (CNS) endothelium. Its deletion resulted embryonic lethality through CNS-specific angiogenesis arrest in forebrain and neural tube. Conversely, GPR124 overexpression throughout all adult vascular beds produced CNSspecific hyperproliferative vascular malformations (Kuhnert, Mancuso et al. 2010). 


\subsection{Adipocyte differentiation}

Adipogenesis is a complex process by a multifaceted transcriptional regulatory cascade. In recent years data have emerged indicating a role of retinoids in adipose tissue. Retinoids has been shown to inhibit preadipocyte to adipocyte differentiation by repressing Ppary and Rxra activities (Ziouzenkova, Orasanu et al. 2007), however we should note that the embryonic stem cell derived adipogenesis requires RA in the very beginning (Bost, Caron et al. 2002). The role of such early RA signal in adipocyte differentiation remained largely unknown.

Cidea (cell death-inducing DNA fragmentation factor, alpha subunit-like effector A) $(\uparrow)$

Cidea-null mice are lean and resistant to diet-induced obesity and diabetes, indicating a role for Cidea in energy balance and adiposity (Zhou, Yon Toh et al. 2003). Thus, Cidea can be a potential RA regulated gene in ES cell that influence the adipocyte differentiation.

Nrip1 (discussed also in "Regulators of RA metabolism” section) ( $\uparrow$ )

Knockout male and female mice are smaller than wild-type littermates. Nrip1-null cells show elevated energy expenditure and express high levels of the uncoupling protein 1 gene (Ucp1), carnitine palmitoyltransferase 1b, and the cell-death-inducing DFF45-like effector A (Cidea) (Christian, Kiskinis et al. 2005).

Rbp1* (retinol binding protein 1, cellular), also known as CRBP1 (discussed also in "Regulators of RA metabolism" section) $(\uparrow)$

Interestingly, a recent study showed that CRBP1-deficient mice fed with high-fat diet (HFD) lead to increased adiposity. Similarly, suppression of CRBP-I expression in vitro enhanced adipocyte differentiation (Zizola, Frey et al. 2010).

Rarb* (discussed also in "Regulators of RA metabolism" section) ( $\uparrow$ )

$\operatorname{Rar} \beta$ activation has been shown that both sufficient and necessary to trigger commitment of mES cells to adipocytes (Monteiro, Wdziekonski et al. 2009).

\section{Future directions}

Microarray completed with ChIP-chip or ChIP-Seq is useful to determine sets of RA regulated genes and map the binding sites of RAR:RXR heterodimer. We have shown that RA treatment of ES cells or EBs induces expression of genes involved in retinoid metabolism, body-axis regulation, gonad development and neural differentiation. Other recently introduced methods, such as RNA-Seq (Wang, Gerstein et al. 2009) and Gro-Seq (Core, Waterfall et al. 2008), still have not been used in retinoid research, and may serve more detailed picture about the direct effect of RA (detailed description of genome-wide approaches in aspect of stem cell research is reviewed in (Zhang and Huang 2010). Future experiments should be complemented with studies investigating the co-occupancy of RAR, RXR, RNA Pol II and coregulators (SMRT, NCoR, NCoA, CBP/p300, etc.) genome-wide to get information about the direct gene regulation and its temporal dynamics. Development of data processing methods and integration of system biology will be also required for analyzing the complexity underlying the regulatory networks in stem cells and during cell fate commitment (Macarthur, Ma'ayan et al. 2009).

There are other technical challenges limiting our recent possibilities. Several cell-type specific differentiation protocol has been published, many of them resulting heterogeneous cell population. This is mainly due to our poor understanding on interactions of different signal cascades. Uncontrolled content of FBS, heterogeneity during EB formation, not adequate 
ligand treatment may also affect the quality of cell culture. For instance, embryonic stem cell derived embryoid bodies often show heterogeneity in their size that may have impact on cell fate commitment (Mansergh, Daly et al. 2009). Adherent monolayer cultures have been used to get more homogenous differentiation. It has been successfully used for neural differentiation (Pachernik, Esner et al. 2002), however many of the lineage differentiation is still require the EB formation, implying the importance of a three-dimensional structure. Replacement of EBs by scaffolds can provide such three-dimensional environment in which cells have access to nutrients and space to grow. Recent studies are using scaffolds to induce high organization of stem cells during differentiation. For instance, one of the most recent study reported the dynamic, autonomous formation of the optic cup structure from a three-dimensional culture of mouse embryonic stem cell aggregates (Eiraku, Takata et al. 2011).

During development, morphogens are secreted locally and presented to embryonic cells in a spatially and temporally controlled manner to direct appropriate differentiation and tissue formation. This seems to be true for RA production as well. In vitro addition of RA to the media of differentiating EBs does not accurately replicate this process. In addition, the diffusion of RA into EBs may be restricted by the formation of an exterior shell composed of collagenous matrix and tight E-cadherin mediated cell-cell adhesions at the EB surface. Biodegradable microspheres to deliver morphogens directly within EBs may enable production of more homogeneous populations of differentiated cells (Bratt-Leal, Carpenedo et al. 2010). A study examined ESC differentiation in response to microsphere-mediated delivery of RA (Li, Davidovich et al. 2011). The authors found that after 10 days of differentiation, the RA microsphere-containing EBs formed large cystic structures that comprised the majority of the EBs. Genome-wide analysis revealed more pronounced upregulation in visceral endoderm, epiblast, and early primitive streak markers and downregulation in mesoderm and definitive endoderm differentiation. Thus, in the existing stem cell differentiation protocols we need to revisit the usefulness of cytokine/ligand delivering microspheres.

Finally, important to note that RT-PCR, western blot or even microarray analysis are able to reveal only the average response of the cell population to a given signal (Figure 4). This is clearly giving only limited information. Single cell analyzing methods will bring us closer to understand the dynamics of cell fate commitment. This field is expected to accelerate soon and will change recently used methodologies.
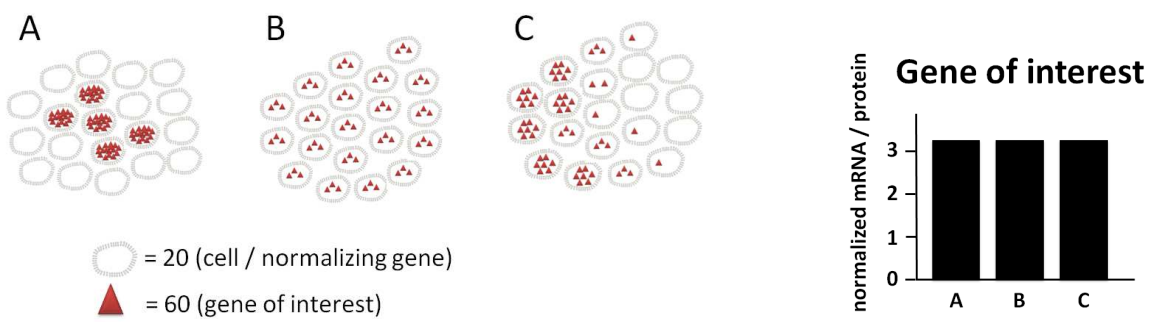

Fig. 4. Population measurements can obscure the heterogeneity of the cells within the embryoid body. For instance, western blot or RT-PCR are not able to determine whether only a few cell are expressing the gene of interest on high level (A), every cell on middle level (B) or there is a polarity (C). 


\section{Conclusions}

Embryonic cells are widely used model system to understand the early steps of embryonic development. Over the last years, many RA-regulated pathways have been discovered in EC and ES cells using a diverse set of techniques. In this chapter we have summarized the results of recent studies using high-throughput approaches (microarray, ChIP-chip, ChIPSeq) to understand the mechanistic of retinoid signaling in early embryonic development. However, many questions remained to be unanswered. We should face the new technical challenges to be able to work out these issues.

\section{References}

Aparicio, O., J. V. Geisberg, et al. (2004). "Chromatin immunoprecipitation for determining the association of proteins with specific genomic sequences in vivo." Curr Protoc Cell Biol Chapter 17: Unit 177.

Azcoitia, V., M. Aracil, et al. (2005). "The homeodomain protein Meis1 is essential for definitive hematopoiesis and vascular patterning in the mouse embryo." Dev Biol 280(2): 307-20.

Bain, D. L., A. F. Heneghan, et al. (2007). "Nuclear receptor structure: implications for function." Annu Rev Physiol 69: 201-20.

Balmer, J. E. and R. Blomhoff (2005). "A robust characterization of retinoic acid response elements based on a comparison of sites in three species." J Steroid Biochem Mol Biol 96(5): 347-54.

Beland, M., N. Pilon, et al. (2004). "Cdx1 autoregulation is governed by a novel Cdx1-LEF1 transcription complex." Mol Cell Biol 24(11): 5028-38.

Bendel-Stenzel, M., R. Anderson, et al. (1998). "The origin and migration of primordial germ cells in the mouse." Semin Cell Dev Biol 9(4): 393-400.

Bibel, M., J. Richter, et al. (2007). "Generation of a defined and uniform population of CNS progenitors and neurons from mouse embryonic stem cells." Nat Protoc 2(5): 1034-43.

Blomhoff, R. and H. K. Blomhoff (2006). "Overview of retinoid metabolism and function." J Neurobiol 66(7): 606-30.

Bost, F., L. Caron, et al. (2002). "Retinoic acid activation of the ERK pathway is required for embryonic stem cell commitment into the adipocyte lineage." Biochem J 361(Pt 3): 621-7.

Bowles, J., D. Knight, et al. (2006). "Retinoid signaling determines germ cell fate in mice." Science 312(5773): 596-600.

Bratt-Leal, A. M., R. L. Carpenedo, et al. (2010). "Incorporation of biomaterials in multicellular aggregates modulates pluripotent stem cell differentiation." Biomaterials 32(1): 48-56.

Capellini, T. D., G. Di Giacomo, et al. (2006). "Pbx1/Pbx2 requirement for distal limb patterning is mediated by the hierarchical control of Hox gene spatial distribution and Shh expression." Development 133(11): 2263-73.

Capellini, T. D., R. Zewdu, et al. (2008). "Pbx1/Pbx2 govern axial skeletal development by controlling Polycomb and Hox in mesoderm and Pax1/Pax9 in sclerotome." Dev Biol 321(2): 500-14.

Casci, T. (2008). "Developmental biology: Retinoic acid passes the morphogen test." Nature Reviews Genetics (9): 7-7. 
Chambon, P. (2005). "The nuclear receptor superfamily: a personal retrospect on the first two decades." Mol Endocrinol 19(6): 1418-28.

Chen, A. C. and L. J. Gudas (1996). "An analysis of retinoic acid-induced gene expression and metabolism in AB1 embryonic stem cells." J Biol Chem 271(25): 14971-80.

Chen, L. and J. S. Khillan (2010). "A novel signaling by vitamin A/retinol promotes self renewal of mouse embryonic stem cells by activating PI3K/Akt signaling pathway via insulin-like growth factor-1 receptor." Stem Cells 28(1): 57-63.

Chen, L., M. Yang, et al. (2007). "Suppression of ES cell differentiation by retinol (vitamin A) via the overexpression of Nanog." Differentiation 75(8): 682-93.

Chithalen, J. V., L. Luu, et al. (2002). "HPLC-MS/MS analysis of the products generated from all-trans-retinoic acid using recombinant human CYP26A." J Lipid Res 43(7): 1133-42.

Chourrout, D., F. Delsuc, et al. (2006). "Minimal ProtoHox cluster inferred from bilaterian and cnidarian Hox complements." Nature 442(7103): 684-7.

Christian, M., E. Kiskinis, et al. (2005). "RIP140-targeted repression of gene expression in adipocytes." Mol Cell Biol 25(21): 9383-91.

Core, L. J., J. J. Waterfall, et al. (2008). "Nascent RNA sequencing reveals widespread pausing and divergent initiation at human promoters." Science 322(5909): 1845-8.

Core, N., X. Caubit, et al. (2007). "Tshz1 is required for axial skeleton, soft palate and middle ear development in mice." Dev Biol 308(2): 407-20.

Cullum, M. E. and M. H. Zile (1985). "Metabolism of all-trans-retinoic acid and all-transretinyl acetate. Demonstration of common physiological metabolites in rat small intestinal mucosa and circulation." J Biol Chem 260(19): 10590-6.

Cvekl, A. and W. L. Wang (2009). "Retinoic acid signaling in mammalian eye development." Exp Eye Res 89(3): 280-91.

D'Ambrosio, D. N., R. D. Clugston, et al. (2011). "Vitamin A Metabolism: An Update." 3(1): 63-103.

Delacroix, L., E. Moutier, et al. (2010). "Cell-specific interaction of retinoic acid receptors with target genes in mouse embryonic fibroblasts and embryonic stem cells." Mol Cell Biol 30(1): 231-44.

Diez del Corral, R. and K. G. Storey (2004). "Opposing FGF and retinoid pathways: a signalling switch that controls differentiation and patterning onset in the extending vertebrate body axis." Bioessays 26(8): 857-69.

Dolle, P. (2009). "Developmental expression of retinoic acid receptors (RARs)." Nucl Recept Signal 7: e006.

Dolle, P., E. Ruberte, et al. (1990). "Retinoic acid receptors and cellular retinoid binding proteins. I. A systematic study of their differential pattern of transcription during mouse organogenesis." Development 110(4): 1133-51.

Duester, G. (2008). "Retinoic acid synthesis and signaling during early organogenesis." Cell 134(6): 921-31.

Duester, G. (2009). "Keeping an eye on retinoic acid signaling during eye development." Chem Biol Interact 178(1-3): 178-81.

Dupe, V., M. Davenne, et al. (1997). "In vivo functional analysis of the Hoxa-1 3' retinoic acid response element (3'RARE)." Development 124(2): 399-410.

Edson, M. A., A. K. Nagaraja, et al. (2009). "The mammalian ovary from genesis to revelation." Endocr Rev 30(6): 624-712.

Eguizabal, C., T. C. Shovlin, et al. (2009). "Generation of primordial germ cells from pluripotent stem cells." Differentiation 78(2-3): 116-23. 
Eiraku, M., N. Takata, et al. (2011). "Self-organizing optic-cup morphogenesis in threedimensional culture." Nature 472(7341): 51-6.

Feng, L., R. E. Hernandez, et al. (2010). "Dhrs3a regulates retinoic acid biosynthesis through a feedback inhibition mechanism." Dev Biol 338(1): 1-14.

Flynn, P. J., W. J. Miller, et al. (1983). "Retinoic acid treatment of acute promyelocytic leukemia: in vitro and in vivo observations." Blood 62(6): 1211-7.

Gaunt, S. J., D. Drage, et al. (2008). "Increased Cdx protein dose effects upon axial patterning in transgenic lines of mice." Development 135(15): 2511-20.

Ghyselinck, N. B., C. Bavik, et al. (1999). "Cellular retinol-binding protein I is essential for vitamin A homeostasis." EMBO J 18(18): 4903-14.

Giguere, V., E. S. Ong, et al. (1987). "Identification of a receptor for the morphogen retinoic acid." Nature 330(6149): 624-9.

Glass, C. K. (1994). "Differential recognition of target genes by nuclear receptor monomers, dimers, and heterodimers." Endocr Rev 15(3): 391-407.

Glass, C. K. and M. G. Rosenfeld (2000). "The coregulator exchange in transcriptional functions of nuclear receptors." Genes Dev 14(2): 121-41.

Gudas, L. J. and J. A. Wagner (2011). "Retinoids regulate stem cell differentiation." J Cell Physiol 226(2): 322-30.

Haeseleer, F., J. Huang, et al. (1998). "Molecular characterization of a novel short-chain dehydrogenase/reductase that reduces all-trans-retinal." J Biol Chem 273(34): 21790-9.

Hamada, H., C. Meno, et al. (2001). "Role of asymmetric signals in left-right patterning in the mouse." Am J Med Genet 101(4): 324-7.

Han, B. C., H. F. Xia, et al. (2010). "Retinoic acid-metabolizing enzyme cytochrome P450 26a1 (cyp26a1) is essential for implantation: functional study of its role in early pregnancy." J Cell Physiol 223(2): 471-9.

Heng, J. C., B. Feng, et al. (2010). "The nuclear receptor Nr5a2 can replace Oct4 in the reprogramming of murine somatic cells to pluripotent cells." Cell Stem Cell 6(2): 16774.

Hisa, T., S. E. Spence, et al. (2004). "Hematopoietic, angiogenic and eye defects in Meis1 mutant animals." EMBO J 23(2): 450-9.

Hogarth, C. A., D. Mitchell, et al. (2011). "Identification and expression of potential regulators of the mammalian mitotic-to-meiotic transition." Biol Reprod 84(1): 34-42.

Honkakoski, P. and M. Negishi (2000). "Regulation of cytochrome P450 (CYP) genes by nuclear receptors." Biochem J 347(Pt 2): 321-37.

Horlein, A. J., A. M. Naar, et al. (1995). "Ligand-independent repression by the thyroid hormone receptor mediated by a nuclear receptor co-repressor." Nature 377(6548): 397-404.

Horst, R. L., T. A. Reinhardt, et al. (1995). "Identification of 9-cis,13-cis-retinoic acid as a major circulating retinoid in plasma." Biochemistry 34(4): 1203-9.

Huang, D., S. W. Chen, et al. (2002). "Analysis of two distinct retinoic acid response elements in the homeobox gene Hoxb1 in transgenic mice." Dev Dyn 223(3): 353-70.

Huang, F. J., C. C. Shen, et al. (2003). "Retinoic acid decreases the viability of mouse blastocysts in vitro." Hum Reprod 18(1): 130-6.

Isken, A., M. Golczak, et al. (2008). "RBP4 disrupts vitamin A uptake homeostasis in a STRA6-deficient animal model for Matthew-Wood syndrome." Cell Metab 7(3): 25868.

Johnson, D. S., A. Mortazavi, et al. (2007). "Genome-wide mapping of in vivo protein-DNA interactions." Science 316(5830): 1497-502. 
Kashyap, V. and L. J. Gudas (2010). "Epigenetic regulatory mechanisms distinguish retinoic acid-mediated transcriptional responses in stem cells and fibroblasts." J Biol Chem 285(19): 14534-48.

Kashyap, V., L. J. Gudas, et al. (2011). "Epigenomic reorganization of the clustered Hox genes in embryonic stem cells induced by retinoic acid." J Biol Chem 286(5): 3250-60.

Kawaguchi, R., J. Yu, et al. (2007). "A membrane receptor for retinol binding protein mediates cellular uptake of vitamin A." Science 315(5813): 820-5.

Koide, T., M. Downes, et al. (2001). "Active repression of RAR signaling is required for head formation." Genes Dev 15(16): 2111-21.

Koubova, J., D. B. Menke, et al. (2006). "Retinoic acid regulates sex-specific timing of meiotic initiation in mice." Proc Natl Acad Sci U S A 103(8): 2474-9.

Kuhnert, F., M. R. Mancuso, et al. (2010). "Essential regulation of CNS angiogenesis by the orphan G protein-coupled receptor GPR124." Science 330(6006): 985-9.

Kumar, S., C. Chatzi, et al. (2011). "Sex-specific timing of meiotic initiation is regulated by Cyp26b1 independent of retinoic acid signalling." Nat Commun 2: 151.

Lane, M. A., A. C. Chen, et al. (1999). "Removal of LIF (leukemia inhibitory factor) results in increased vitamin A (retinol) metabolism to 4-oxoretinol in embryonic stem cells." Proc Natl Acad Sci U S A 96(23): 13524-9.

Langston, A. W. and L. J. Gudas (1992). "Identification of a retinoic acid responsive enhancer 3' of the murine homeobox gene Hox-1.6." Mech Dev 38(3): 217-27.

Langston, A. W., J. R. Thompson, et al. (1997). "Retinoic acid-responsive enhancers located 3' of the Hox A and Hox B homeobox gene clusters. Functional analysis." J Biol Chem 272(4): 2167-75.

Langton, S. and L. J. Gudas (2008). "CYP26A1 knockout embryonic stem cells exhibit reduced differentiation and growth arrest in response to retinoic acid." Dev Biol 315(2): 331-54.

Ledda-Columbano, G. M., M. Pibiri, et al. (2004). "Induction of hepatocyte proliferation by retinoic acid." Carcinogenesis 25(11): 2061-6.

Lee, J., T. Yokota, et al. (2002). "Analyses of mRNA expression patterns of cohesin subunits Rad21 and Rec8 in mice: germ cell-specific expression of rec8 mRNA in both male and female mice." Zoolog Sci 19(5): 539-44.

Li, H. and M. Clagett-Dame (2009). "Vitamin A deficiency blocks the initiation of meiosis of germ cells in the developing rat ovary in vivo." Biol Reprod 81(5): 996-1001.

Li, L., A. E. Davidovich, et al. (2011). "Neural lineage differentiation of embryonic stem cells within alginate microbeads." Biomaterials.

Lin, T. C., J. M. Yen, et al. (2003). "IGF-1/IGFBP-1 increases blastocyst formation and total blastocyst cell number in mouse embryo culture and facilitates the establishment of a stem-cell line." BMC Cell Biol 4: 14.

Loudig, O., G. A. Maclean, et al. (2005). "Transcriptional co-operativity between distant retinoic acid response elements in regulation of Cyp26A1 inducibility." Biochem J 392(Pt 1): 241-8.

Luo, J., P. Pasceri, et al. (1995). "Mice lacking all isoforms of retinoic acid receptor beta develop normally and are susceptible to the teratogenic effects of retinoic acid." Mech Dev 53(1): 61-71.

Macarthur, B. D., A. Ma'ayan, et al. (2009). "Systems biology of stem cell fate and cellular reprogramming." Nat Rev Mol Cell Biol 10(10): 672-81.

Mahony, S., E. O. Mazzoni, et al. (2011). "Ligand-dependent dynamics of retinoic acid receptor binding during early neurogenesis." Genome Biol 12(1): R2. 
Mansergh, F. C., C. S. Daly, et al. (2009). "Gene expression profiles during early differentiation of mouse embryonic stem cells." BMC Dev Biol 9: 5.

Mark, M., N. B. Ghyselinck, et al. (2009). "Function of retinoic acid receptors during embryonic development." Nucl Recept Signal 7: e002.

Martinez-Ceballos, E. and L. J. Gudas (2008). "Hoxa1 is required for the retinoic acidinduced differentiation of embryonic stem cells into neurons." J Neurosci Res 86(13): 2809-19.

McKinney-Freeman, S. L., C. Lengerke, et al. (2008). "Modulation of murine embryonic stem cell-derived CD41+c-kit+ hematopoietic progenitors by ectopic expression of $\mathrm{Cdx}$ genes." Blood 111(10): 4944-53.

Mercola, M. and M. Levin (2001). "Left-right asymmetry determination in vertebrates." Annu Rev Cell Dev Biol 17: 779-805.

Meyers, E. N. and G. R. Martin (1999). "Differences in left-right axis pathways in mouse and chick: functions of FGF8 and SHH." Science 285(5426): 403-6.

Mic, F. A., A. Molotkov, et al. (2003). "Retinoid activation of retinoic acid receptor but not retinoid $X$ receptor is sufficient to rescue lethal defect in retinoic acid synthesis." Proc Natl Acad Sci U S A 100(12): 7135-40.

Moens, C. B. and L. Selleri (2006). "Hox cofactors in vertebrate development." Dev Biol 291(2): 193-206.

Molyneaux, K. A., H. Zinszner, et al. (2003). "The chemokine SDF1/CXCL12 and its receptor CXCR4 regulate mouse germ cell migration and survival." Development 130(18): 4279-86.

Monteiro, M. C., B. Wdziekonski, et al. (2009). "Commitment of mouse embryonic stem cells to the adipocyte lineage requires retinoic acid receptor beta and active GSK3." Stem Cells Dev 18(3): 457-63.

Mummery, C. L., M. A. van Rooijen, et al. (1987). "Cell cycle analysis during retinoic acid induced differentiation of a human embryonal carcinoma-derived cell line." Cell Differ 20(2-3): 153-60.

Nagy, L., H. Y. Kao, et al. (1997). "Nuclear receptor repression mediated by a complex containing SMRT, mSin3A, and histone deacetylase." Cell 89(3): 373-80.

Niederreither, K. and P. Dolle (2008). "Retinoic acid in development: towards an integrated view." Nat Rev Genet 9(7): 541-53.

Niederreither, K., V. Subbarayan, et al. (1999). "Embryonic retinoic acid synthesis is essential for early mouse post-implantation development." Nat Genet 21(4): 444-8.

Noy, N. (1992). "The ionization behavior of retinoic acid in aqueous environments and bound to serum albumin." Biochim Biophys Acta 1106(1): 151-8.

Okada, Y., T. Shimazaki, et al. (2004). "Retinoic-acid-concentration-dependent acquisition of neural cell identity during in vitro differentiation of mouse embryonic stem cells." Dev Biol 275(1): 124-42.

Oulad-Abdelghani, M., P. Bouillet, et al. (1996). "Characterization of a premeiotic germ cellspecific cytoplasmic protein encoded by Stra8, a novel retinoic acid-responsive gene." J Cell Biol 135(2): 469-77.

Pachernik, J., M. Esner, et al. (2002). "Neural differentiation of mouse embryonic stem cells grown in monolayer." Reprod Nutr Dev 42(4): 317-26.

Packer, A. I., D. A. Crotty, et al. (1998). "Expression of the murine Hoxa4 gene requires both autoregulation and a conserved retinoic acid response element." Development 125(11): 1991-8. 
Pasutto, F., H. Sticht, et al. (2007). "Mutations in STRA6 cause a broad spectrum of malformations including anophthalmia, congenital heart defects, diaphragmatic hernia, alveolar capillary dysplasia, lung hypoplasia, and mental retardation." Am J Hum Genet 80(3): 550-60.

Pennimpede, T., D. A. Cameron, et al. (2010). "The role of CYP26 enzymes in defining appropriate retinoic acid exposure during embryogenesis." Birth Defects Res A Clin Mol Teratol 88(10): 883-94.

Petkovich, M., N. J. Brand, et al. (1987). "A human retinoic acid receptor which belongs to the family of nuclear receptors." Nature 330(6147): 444-50.

Pikarsky, E., H. Sharir, et al. (1994). "Retinoic acid represses Oct-3/4 gene expression through several retinoic acid-responsive elements located in the promoter-enhancer region." Mol Cell Biol 14(2): 1026-38.

Popperl, H. and M. S. Featherstone (1993). "Identification of a retinoic acid response element upstream of the murine Hox-4.2 gene." Mol Cell Biol 13(1): 257-65.

Qi, X., T. G. Li, et al. (2004). "BMP4 supports self-renewal of embryonic stem cells by inhibiting mitogen-activated protein kinase pathways." Proc Natl Acad Sci U S A 101(16): 6027-32.

Ray, W. J., G. Bain, et al. (1997). "CYP26, a novel mammalian cytochrome P450, is induced by retinoic acid and defines a new family." J Biol Chem 272(30): 18702-8.

Riddle, R. D., R. L. Johnson, et al. (1993). "Sonic hedgehog mediates the polarizing activity of the ZPA." Cell 75(7): 1401-16.

Rochette-Egly, C. (2005). "Dynamic combinatorial networks in nuclear receptor-mediated transcription." J Biol Chem 280(38): 32565-8.

Rossi, A., O. F. D'Urso, et al. (2010). "Non-coding RNAs change their expression profile after Retinoid induced differentiation of the promyelocytic cell line NB4." BMC Res Notes 3: 24 .

Saunders, J. W., JR and Gasseling, M. T. (1968). "Ectodermal-mesodermal interactions in the origin of limb symmetry." Epithelial-Mesenchymal Interactions in Development: pp. 7879.

Selleri, L., J. DiMartino, et al. (2004). "The TALE homeodomain protein Pbx2 is not essential for development and long-term survival." Mol Cell Biol 24(12): 5324-31.

Silva, J. and A. Smith (2008). "Capturing pluripotency." Cell 132(4): 532-6.

Simandi, Z., B. L. Balint, et al. (2010). "Activation of retinoic acid receptor signaling coordinates lineage commitment of spontaneously differentiating mouse embryonic stem cells in embryoid bodies." FEBS Lett 584(14): 3123-30.

Sirbu, I. O., L. Gresh, et al. (2005). "Shifting boundaries of retinoic acid activity control hindbrain segmental gene expression." Development 132(11): 2611-22.

Slack, J. M. (1987). "Embryology: we have a morphogen!" Nature 327(6123): 553-4.

Soprano, D. R., B. W. Teets, et al. (2007). "Role of retinoic acid in the differentiation of embryonal carcinoma and embryonic stem cells." Vitam Horm 75: 69-95.

Subramanian, V., B. I. Meyer, et al. (1995). "Disruption of the murine homeobox gene Cdx1 affects axial skeletal identities by altering the mesodermal expression domains of Hox genes." Cell 83(4): 641-53.

Takahashi, K. and S. Yamanaka (2006). "Induction of pluripotent stem cells from mouse embryonic and adult fibroblast cultures by defined factors." Cell 126(4): 663-76.

Tedesco, M., G. La Sala, et al. (2009). "STRA8 shuttles between nucleus and cytoplasm and displays transcriptional activity." J Biol Chem 284(51): 35781-93. 
Thaller, C. and G. Eichele (1987). "Identification and spatial distribution of retinoids in the developing chick limb bud." Nature 327(6123): 625-8.

Tickle, C., B. Alberts, et al. (1982). "Local application of retinoic acid to the limb bond mimics the action of the polarizing region." Nature 296(5857): 564-6.

Tighe, A. P. and L. J. Gudas (2004). "Retinoic acid inhibits leukemia inhibitory factor signaling pathways in mouse embryonic stem cells." J Cell Physiol 198(2): 223-9.

Tucker, E. S., S. Segall, et al. (2008). "Molecular specification and patterning of progenitor cells in the lateral and medial ganglionic eminences." J Neurosci 28(38): 9504-18.

Umesono, K., V. Giguere, et al. (1988). "Retinoic acid and thyroid hormone induce gene expression through a common responsive element." Nature 336(6196): 262-5.

Vansant, G. and W. F. Reynolds (1995). "The consensus sequence of a major Alu subfamily contains a functional retinoic acid response element." Proc Natl Acad Sci U S A 92(18): 8229-33.

Wang, Z., M. Gerstein, et al. (2009). "RNA-Seq: a revolutionary tool for transcriptomics." Nat Rev Genet 10(1): 57-63.

Warkany, J. (1954). "Disturbance of embryonic development by maternal vitamin deficiencies." J Cell Physiol Suppl 43(Suppl. 1): 207-36.

White, R., G. Leonardsson, et al. (2000). "The nuclear receptor co-repressor nrip1 (RIP140) is essential for female fertility." Nat Med 6(12): 1368-74.

Williams, R. L., D. J. Hilton, et al. (1988). "Myeloid leukaemia inhibitory factor maintains the developmental potential of embryonic stem cells." Nature 336(6200): 684-7.

Wilson, J. G. and J. Warkany (1947). "Anomalies of the genito-urinary tract induced by maternal vitamin A deficiency in fetal rats." Anat Rec 97(3): 376.

Wilson, J. G. and J. Warkany (1950). "Congenital anomalies of heart and great vessels in offspring of vitamin A-deficient rats." Am J Dis Child 79(5): 963.

Xu, H., M. D. Beasley, et al. (2005). "Absence of mouse REC8 cohesin promotes synapsis of sister chromatids in meiosis." Dev Cell 8(6): 949-61.

Ying, Q. L., J. Wray, et al. (2008). "The ground state of embryonic stem cell self-renewal." Nature 453(7194): 519-23.

Ying, Y. and G. Q. Zhao (2001). "Cooperation of endoderm-derived BMP2 and extraembryonic ectoderm-derived BMP4 in primordial germ cell generation in the mouse." Dev Biol 232(2): 484-92.

Young-Pearse, T. L., L. Ivic, et al. (2006). "Characterization of mice with targeted deletion of glycine receptor alpha 2." Mol Cell Biol 26(15): 5728-34.

Yuki, K., H. Shindou, et al. (2009). "Characterization of mouse lysophosphatidic acid acyltransferase 3: an enzyme with dual functions in the testis." J Lipid Res 50(5): 860-9.

Zhang, X. and J. Huang (2010). "Integrative genome-wide approaches in embryonic stem cell research." Integr Biol (Camb) 2(10): 510-6.

Zhang, Y. Q., L. Sterling, et al. (2008). "Nodal and lefty signaling regulates the growth of pancreatic cells." Dev Dyn 237(5): 1255-67.

Zhou, G. B., Q. G. Meng, et al. (2010). "In vitro derivation of germ cells from embryonic stem cells in mammals." Mol Reprod Dev 77(7): 586-94.

Zhou, Z., S. Yon Toh, et al. (2003). "Cidea-deficient mice have lean phenotype and are resistant to obesity." Nat Genet 35(1): 49-56.

Ziouzenkova, O., G. Orasanu, et al. (2007). "Retinaldehyde represses adipogenesis and dietinduced obesity." Nat Med 13(6): 695-702.

Zizola, C. F., S. K. Frey, et al. (2010). "Cellular retinol-binding protein type I (CRBP-I) regulates adipogenesis." Mol Cell Biol 30(14): 3412-20. 


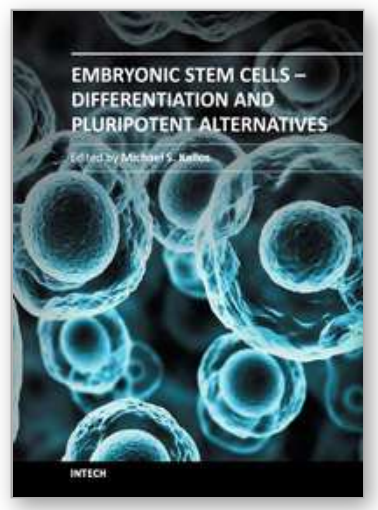

\author{
Embryonic Stem Cells - Differentiation and Pluripotent Alternatives \\ Edited by Prof. Michael S. Kallos
}

ISBN 978-953-307-632-4

Hard cover, 506 pages

Publisher InTech

Published online 12, October, 2011

Published in print edition October, 2011

The ultimate clinical implementation of embryonic stem cells will require methods and protocols to turn these unspecialized cells into the fully functioning cell types found in a wide variety of tissues and organs. In order to achieve this, it is necessary to clearly understand the signals and cues that direct embryonic stem cell differentiation. This book provides a snapshot of current research on the differentiation of embryonic stem cells to a wide variety of cell types, including neural, cardiac, endothelial, osteogenic, and hepatic cells. In addition, induced pluripotent stem cells and other pluripotent stem cell sources are described. The book will serve as a valuable resource for engineers, scientists, and clinicians as well as students in a wide range of disciplines.

\title{
How to reference
}

In order to correctly reference this scholarly work, feel free to copy and paste the following:

Zoltan Simandi and Laszlo Nagy (2011). Retinoid Signaling is a Context-Dependent Regulator of Embryonic Stem Cells, Embryonic Stem Cells - Differentiation and Pluripotent Alternatives, Prof. Michael S. Kallos (Ed.), ISBN: 978-953-307-632-4, InTech, Available from: http://www.intechopen.com/books/embryonic-stem-cellsdifferentiation-and-pluripotent-alternatives/retinoid-signaling-is-a-context-dependent-regulator-of-embryonicstem-cells

\section{INTECH}

open science | open minds

\section{InTech Europe}

University Campus STeP Ri

Slavka Krautzeka 83/A

51000 Rijeka, Croatia

Phone: +385 (51) 770447

Fax: +385 (51) 686166

www.intechopen.com

\section{InTech China}

Unit 405, Office Block, Hotel Equatorial Shanghai

No.65, Yan An Road (West), Shanghai, 200040, China

中国上海市延安西路65号上海国际贵都大饭店办公楼405单元

Phone: +86-21-62489820

Fax: +86-21-62489821 
(C) 2011 The Author(s). Licensee IntechOpen. This is an open access article distributed under the terms of the Creative Commons Attribution 3.0 License, which permits unrestricted use, distribution, and reproduction in any medium, provided the original work is properly cited. 